\title{
Fetal stem cells and skeletal muscle regeneration: a therapeutic approach
}

\author{
Michela Pozzobon ${ }^{1}$, Chiara Franzin ${ }^{1}$, Martina Piccoli ${ }^{1}$ and Paolo De Coppi ${ }^{2 *}$ \\ ' Fondazione Istituto di Ricerca Pediatrica Città della Speranza, Padova, Italy \\ ${ }^{2}$ UCL Institute of Child Health and Great Ormond Street Hospital, London, UK
}

\section{Edited by:}

Paolo Bonaldo, University of Padova Italy

Reviewed by:

Anna Maria Colangelo, University of Milano-Bicocca, Italy

Maria Roubelakis, University of Athens Medical School, Greece

\section{${ }^{*}$ Correspondence.}

Paolo De Coppi, UCL Institute of Child Health and Great Ormond

Street Hospital, 30 Guilford Street, London WC1N 1EH, UK

e-mail:paolo.decoppi@gosh.nhs.uk
More than $40 \%$ of the body mass is represented by muscle tissue, which possesses the innate ability to regenerate after damage through the activation of muscle-specific stem cells, namely satellite cells. Muscle diseases, in particular chronic degenerative states of skeletal muscle such as dystrophies, lead to a perturbation of the regenerative process, which causes the premature exhaustion of satellite cell reservoir due to continuous cycles of degeneration/regeneration. Nowadays, the research is focused on different therapeutic approaches, ranging from gene and cell to pharmacological therapy, but still there is no definitive cure in particular for genetic muscle disease. Keeping this in mind, in this article, we will give special consideration to muscle diseases and the use of fetal derived stem cells as a new approach for therapy. Cells of fetal origin, from cord blood to placenta and amniotic fluid, can be easily obtained without ethical concern, expanded and differentiated in culture, and possess immune-modulatory properties. The in vivo approach in animal models can be helpful to study the mechanism underneath the operating principle of the stem cell reservoir, namely the niche, which holds great potential to understand the onset of muscle pathologies.

Keywords: fetal cells, muscle dystrophies, cell therapy, placenta, cord blood, amniotic fluid

\section{INTRODUCTION}

The muscular dystrophies are heterogeneous genetic diseases that strongly impair skeletal muscle structure and function. These disorders are caused by mutations in genes encoding for structural proteins essential for muscle integrity, and depending on the alteration, it is possible to distinguish dystrophies due to (i) mutations on a specific gene, such as Duchenne muscular dystrophy (DMD) or on distinct genes, e.g., limb-girdle muscular dystrophies (LGMD); (ii) epigenetic alterations, for instance facioscapulohumeral muscular dystrophy; and (iii) repeat expansion, such as myotonic dystrophy. The primary genetic defect results in a wide range of pathological phenotypes, different for fashion of inheritance, age of onset, severity and distribution of muscle weakness, and speed of progression (Leung and Wagner, 2013).

In particular, DMD is the most prevalent and severe dystrophy that affects skeletal muscle. It is an X-linked recessive disease due to mutations on dystrophin gene, which determines the production of a truncated and non-functional protein. Dystrophin functions as a muscle fiber stabilizer by linking the cytoplasmic actin filaments with the extracellular matrix. The DMD muscle is characterized by continuous fiber damage, which results in an altered regenerative turnover thus leading to the premature exhaustion of muscle stem cell compartment, the development of chronic inflammation, and the infiltration of adipose and fibrotic tissues. In DMD patients, the muscle loss begins very early in childhood starting from lower extremities and leading to progressive difficulty with walking, and finally, up to the confinement in a wheelchair. In addition to loss of mobility, the major disabling comorbidities are represented by heart disease and respiratory failure that are the most common causes of death (Wilschut et al., 2012; Kharraz et al., 2014). In 1984, Bulfield and co-workers described an X chromosome-linked mutant mouse, also called $m d x$, which mimics the human DMD showing elevated plasma levels of muscle creatine kinase and pyruvate kinase and histological lesions characteristic of muscular dystrophies, although with a milder phenotype (Bulfield et al., 1984). In 2010, Sacco et al. (2010) created a new mouse model where $m d x$ mutation was associated with the loss of telomerase (mTR) activity. Indeed, these doubleknockout mice display a more severe as well as rapidly progressing phenotype and a greatly reduced life span. In order to allow human cell transplantation for preclinical studies, immunocompromised $m d x$ mouse strains have been created, such as $m d x$ nude mice (Partridge et al., 1989) and NOD/Rag $1^{\text {null }} m d x 5^{c v}$ mice (Lapan et al., 2012).

Limb-girdle muscular dystrophies are a family of diseases affecting mainly proximal muscle, in particular shoulders, upper arms, pelvic area, and thighs. These disorders are caused by mutation in various genes encoding muscle structural proteins and present different inheritance patterns; therefore, they consistently differ in terms of age of onset, progress, and severity of disease (Mitsuhashi and Kang, 2012). There are many mouse models for LGMD, according to the variety of involved genes and genetic defects that result in this family of muscle dystrophies. For example, knockout mice for $\alpha$-sarcoglycan gene accurately resemble the LGMD-2D phenotype (Duclos et al., 1998), a deletion on dysferlin gene produces a LGMD-2B phenotype in SJL-Dysf mice (Bittner et al., 1999), while mice carrying mutations on myotilin gene develop the autosomal dominant LGMD-1A (Liu et al., 2014). 
Beside these muscle-specific diseases, there are pathologies that arise from other tissues and consequently affect skeletal muscle. Since the close interplay between nervous system and skeletal muscle compartment, many of these disorders are related to neural degeneration, which causes muscle loss. One example is spinal muscular atrophy (SMA), an autosomal recessive disorder characterized by degeneration of anterior horn neurons and consequent muscle weakness and atrophy. The incidence of SMA is about one in 10,000 live births. It was first described at the end of nineteenth century and only 100 years later the genetic defect was found and localized in the chromosome 5 cared by survival motor neuron (SMN) gene (Gilliam et al., 1990; Lefebvre et al., 1995). In humans, there are normally two copies of SMN gene, SMN1 is essential to the pathogenesis, while the number of copies of SMN2 determines the severity of the disease (Lorson et al., 1998; Feldkotter et al., 2002). Different strategies have been deployed to create murine model of SMA, and using the cre-loxP system the loss of function of Smn gene has been directed toward specific tissues, in particular to skeletal muscle. The mouse model HSA$\mathrm{Cre}, S m n^{F 7 / F 7}$ allows to evaluate the effect of Smn knockout on muscle since the Cre-recombinase is placed under the control of alpha skeletal actin (Nicole et al., 2003). For this reason, mutant mice display pathological features that mimic a muscle dystrophy phenotype, such as muscle weakness and atrophy and chest deformation with consequent respiratory failure (Cifuentes-Diaz et al., 2001; Salah-Mohellibi et al., 2006).

The research is currently focused on three main therapeutic approaches for muscle diseases. Gene therapy aims to restore the dystrophin protein complex through different strategies, ranging from the development of new vectors capable of delivering efficiently the missing gene to the postmitotic nuclei of the muscle fibers, to exon skipping and the enhancement of the synthesis of proteins such as utrophin. The pharmacological approach is mainly focused on the attenuation of the inflammation (corticosteroids administration) and the treatment of co-morbidities (cardiomyopathy, osteoporosis, respiratory failure). Nowadays, new compounds modulating muscle-specific neuronal nitric oxide synthase (nNOS $\mu$ ) pathway and TGF $\beta$ pathway are under investigation (Berardi et al., 2014). The cell therapy approach is devoted to functionally rescue the tissue through cell delivery; so far, in place of muscle satellite cells, other cells isolated from embryonic (Filareto et al., 2013) and adult [pericytes, bone marrow, mesangioblasts (Ferrari et al., 1998; Gussoni et al., 1999; Sampaolesi et al., 2006; Dellavalle et al., 2011)] sources or induced pluripotent stem (iPS) cells (Darabi et al., 2012; Tedesco et al., 2012) have been shown to contribute to muscle regeneration. However, except for embryonic cells, a real integration of administered cells in muscle niche has barely been observed. Recently, mesenchymal stem cells (MSCs) from human fetal blood (Chang et al., 2006) and skeletal muscle progenitors from mouse embryo (Sakai et al., 2013) have been used in muscle regeneration. Several studies demonstrated that fetal tissues are abundant sources of MSCs, including term placenta, fetal bone marrow, blood, lung, liver, and spleen (in 't Anker et al., 2003; Fukuchi et al., 2004), but the most available and easy sources to obtain fetal stem cells are placenta, cord blood, Wharton's jelly, and amniotic fluid (AF).

\section{FETAL STEM CELLS AND MUSCLE REGENERATION}

Research on fetal stem cells and muscle is quite recent. Placenta, cord blood, and AF represent an easy source of stem cells without ethical concerns and are immune-privileged tissues (Toda et al., 2007; Wang et al., 2009; Di Trapani et al., 2013). Placenta has been primarily used as a membrane to treat burns, injuries, and skin ulcers (Bujang-Safawi et al., 2010) and it has been studied also to treat lung fibrosis (Cargnoni et al., 2009) and inflammatory corneal diseases (Dekaris and Gabric, 2009). Cord blood has been considered mainly as a source of hematopoietic cells (Cairo and Wagner, 1997), although new field of applications such as diabetes are open (Zhao et al., 2012). Amniotic fluid stem (AFS) cells recently found applications from the heart (Bollini et al., 2011) to the kidney (Rota et al., 2011) and the lung (Carraro et al., 2008).

This review will evaluate the use of cells from the above mentioned sources in muscle regeneration (Table 1), focusing on both the limits and future potential for therapy.

\section{CORD BLOOD AND WHARTON'S JELLY CELLS}

Umbilical cord connects the fetus to the placenta; it develops from the body stalk of the embryo and contains blood vessels and Wharton's jelly, surrounded by the amnion. Umbilical cord blood (UCB) supplies the developing fetus of nutrients and oxygen through the umbilical vein.

Umbilical cord blood possesses three main types of stem cells that are of interest in regenerative medicine: (1) hematopoietic stem cells, (2) MSCs, and (3) non-hematopoietic multipotent stem cells characterized by the expression of SSEA-4, the transcription factors OCT4, SOX2, and NANOG usually expressed by pluripotent stem cells (McGuckin et al., 2005, 2008; Kucia et al., 2007; Zuba-Surma et al., 2009). The blood vessels of the cord blood are insulated with the gelatinous connective tissue called Wharton's jelly that prevents vein compression (Ferguson and Dodson, 2009). The cells isolated from this biological source share properties with MSCs from UCB such as differentiation ability (Anzalone et al., 2010). Upon in vitro muscle differentiation, $\mathrm{CD}_{105^{+}}$cells form Wharton's jelly have been injected in injured rat Tibialis anterior muscle and after 15 days a mild muscle regeneration has been detected (Conconi et al., 2006).

The involvement of UCB in therapeutic application was reported since 1972, when clinicians treated one case of lymphoblastic leukemia (Ende and Ende, 1972). Nowadays, the translational potential of the clinical applications of UCB stem cells is increased due to important advantages such as the ease to recover the cells right after birth without any risk for the donor, the lack of ethical issues, the low onset of graft-versus-host disease (GVHD) (Broxmeyer et al., 1989; Ballen, 2005; Schoemans et al., 2006; Brunstein et al., 2007; Hwang et al., 2007; Broxmeyer, 2010), and finally the high proliferation rate and long telomere maintenance (Kim et al., 1999; Pipes et al., 2006). Starting from 2003, Pesce and co-workers demonstrated muscle amelioration after injection of $\mathrm{CD}^{+}{ }^{+} \mathrm{UCB}$ cells in injured adductor muscle and new $\mathrm{MYOD}^{+}$ cells of UCB origin (Pesce et al., 2003) in a CD1 mouse model of hindlimb ischemia. Later, in 2007, Koponen and colleagues, using ischemia damage in the immunocompromised BALB/cA-nu mouse, analyzed both endothelium and muscle after local injection of several cell types, namely UCB CD133 ${ }^{+}, \mathrm{CD}_{3}{ }^{+}, \mathrm{MSCs}$, 
Table 1 | Different fetal stem cells displayed myogenic differentiation ability

\begin{tabular}{|c|c|c|c|}
\hline Perinatal sources & Mouse model/injury & Engraftment & Reference \\
\hline \multicolumn{4}{|l|}{ HUMAN ORIGIN } \\
\hline UCB $\left(\mathrm{CD} 34^{+}\right)$ & Sjl-Disf & Yes, 12 weeks post injection & Kong et al. (2004) \\
\hline UCB (MSCs, CD133) & $\begin{array}{l}\text { Balb/cA-nu: hindlimb ischemia } \\
\text { damage }\end{array}$ & No & Koponen et al. (2007) \\
\hline UCB (MSCs) & $M d x$ & Yes, Dys ${ }^{+}$fibers 45 days post local injection & Nunes et al. (2007) \\
\hline UCB $\left(\mathrm{CD} 34^{+}\right)$ & CD1: hindlimb ischemia damage & MyoD $^{+}$cells & Pesce et al. (2003) \\
\hline Wharton's jelly & Lewis rat: bupivacaine injury & Yes, 15 days post local injection & Conconi et al. (2006) \\
\hline Placenta & In vitro only & Lentiviral transfection with MyoD & Akizawa et al. (2013) \\
\hline Placenta & $\mathrm{SCID} / \mathrm{mdx}$ & Yes, 4 weeks post injection & Kawamichi et al. (2010) \\
\hline $\begin{array}{l}\text { Placenta }\left(\mathrm{CD} 146^{+}, \mathrm{CD}^{+} 4^{+},\right. \\
\left.\mathrm{CD}^{-} 6^{-} \mathrm{CD}^{-} 4^{-}\right)\end{array}$ & $\mathrm{SCID} / \mathrm{mdx}$ & Yes, 4 weeks post injection & Park et al. (2010) \\
\hline AF c-Kit cells & SCID & No & Gekas et al. (2010) \\
\hline AFS cells & BALB/cSIc-nu & Yes, 21 days post injection & Kim et al. (2013) \\
\hline AFS cells & NOD/SCID & Yes, 4 weeks post injection & Ma et al. (2012) \\
\hline \multicolumn{4}{|l|}{ MOUSE ORIGIN } \\
\hline AFS cells & HSA-Cre, Smn F7/F7 & $\begin{array}{l}\text { Yes, } 1 \text { and } 15 \text { month post injection and after } \\
\text { secondary transplant }\end{array}$ & Piccoli et al. (2012) \\
\hline
\end{tabular}

VEGF-D, or eGFP transduced cells, highlighting that the skeletal muscle regeneration was an indirect effect of cytokines, such as VEGF and FGF, released by the injected progenitor cells (Koponen et al., 2007).

In the $m d x$ mouse, Nunes and colleagues were able to find a small number of human dystrophin-positive fibers 45 days after injection of $\mathrm{CD} 34^{+} \mathrm{UCB}$ cells in quadriceps muscle. In the murine model of LGMD-2B, the SJL-Dysf mouse, whole UCB, and CD34 ${ }^{ \pm}$ subgroups are engrafted in muscles after systemic injection (Nunes et al., 2007), and expression of dysferlin and human dystrophin was detected 12 weeks post injection of different subpopulation of UCB cells, although in a small amount (Kong et al., 2004).

\section{PLACENTA STEM CELLS}

The placenta develops at the feto-maternal interface and is a temporary organ that grows during pregnancy. It is formed by fetal (amnion and chorionic plate) and maternal (decidua) portions and contains different types of cells. Indeed, the placenta is rich in stem/progenitor cells. While in the amnion human amniotic epithelial cells, which express embryonic stem cell markers, have been isolated (epiblast-derived pluripotent/multipotent stem cells) (Prusa and Hengstschlager, 2002; Miki et al., 2005, 2007), the placenta MSCs have been separated not only from amnion, but also chorion and decidua (Huang et al., 2009; Pozzobon et al., 2014). These cells share with the adult MSCs the spindle-shape appearance and the property to adhere to plastic and to expand. Moreover, placenta MSCs expand faster in vitro and are more immunosuppressive and less immunogenic than the adult MSCs (Battula et al., 2008; Brooke et al., 2008). Recently, a specific subgroup of cells isolated from the human placenta villi and relevant for muscle regeneration, namely the perivascular multipotent mesenchymal progenitor cells, have been characterized by Park et al. (2010). In this research, they studied the angiogenic and myogenic potential of the $\mathrm{CD} 146^{+} \mathrm{CD} 45^{-} \mathrm{CD} 34^{-}$ $\mathrm{CD}^{-} 6^{-}$cells (pericytes fraction) and $\mathrm{CD} 146^{-} \mathrm{CD} 45^{-} \mathrm{CD} 34^{-}$ $\mathrm{CD}^{-} 6^{-}$cells (non-pericytes fraction). When these cell populations were intramuscularly implanted into damaged Gastrocnemius of immunodeficient dystrophic mice, fibers positive for human dystrophin were found at the periphery of the damaged area. The combination of perivascular progenitors together with the multipotent MSCs isolated from the placenta enhanced the migration and regeneration capacity of the placenta stem cells demonstrating that this extra-embryonic tissue is a reservoir of stem/progenitor cells with myogenic potential. The in vitro myogenic differentiation of cells from chorionic plate has been recently documented (Kawamichi et al., 2010) using a standard chemical treatment of inducing myoblasts formation (5-azacytidine) and also forcing $M Y O D$ expression through a lentiviral vector (Akizawa et al., 2013). Kawamichi and colleagues proved also the in vivo ability of placenta-derived cells to ameliorate the dystrophic phenotype of $m d x$ mice inducing the appearance of newly formed fibers expressing human dystrophin.

\section{AMNIOTIC FLUID STEM CELLS}

Amniotic fluid contains a heterogeneous population of cells displaying a wide range of morphologies. Most of these cells are epithelial in nature and have a limited capacity to proliferate in culture. Traditionally, AF has been used for decades as a tool for prenatal diagnosis, but recent studies provided important evidences about the potential of AF as an alternative source of stem cells. Many works have characterized putative stem cell populations isolated from AF, such as Prusa et al. (2003) that showed 
the expression of OCT4 within a subset of AF cells. Moreover, demonstration of proliferation within this population suggests that pluripotent stem cells can be isolated and propagated from the human AF.

Employing immunoselection technique, AF cells expressing the cell surface antigen c-Kit were purified from primary amniocentesis cultures (De Coppi et al., 2007). Isolated cells, called AFS cells, grew rapidly in culture, display a normal karyotype and maintain telomere length during long-term culture. This latter attribute facilitated the establishment of clonal lines from AFS cells, necessary to establish the "stemness" of a population. Clonal AFS cell lines differentiated in vitro to putative adipocytes, endothelial cells, hepatocytes, osteocytes, myocytes, and neurons, derivatives of all germ layers. This broad plasticity appeared to be a general attribute of the selected cells: 19 different amniocentesis cultures yielded multipotent AFS cell clonal lines. A subsequent report demonstrated the AFS cells in vitro chondrogenic differentiation thus providing further evidence of the plasticity and clinical potential of cells isolated from the AF (Preitschopf et al., 2012). Moreover, these cells displayed the ability to reconstitute the depleted bone marrow of Rag1 $1^{-1-}$ mice after systemic injection and secondary transplantation (Ditadi et al., 2009).

Another peculiar characteristic of AFS cells is indeed the ability to pass through the endothelial barrier, thus they can be administered locally or systemically, which represents a great advantage in treating whole body diseases such as muscle dystrophies. Considering this important aspect, mouse AFS cells were used in the $H S A-C r e, S m n^{F 7 / F 7}$ mouse model by transplantation via tail vein (Piccoli et al., 2012). After injection, AFS cells demonstrated remarkable ability to differentiate directly in vivo into myogenic cells but most importantly were able to generate new muscle fibers after cardiotoxin injury or secondary transplant, suggesting the idea that AFS cells are capable of differentiating also in skeletal muscle stem cells repopulating the muscle niche. In this work, the use of freshly isolated or expanded murine AFS cells generated similar results, but it is worth noticing that, with human AFS cells, muscle lineage differentiation becomes difficult to obtain after in vitro expansion. Gekas and colleagues indeed, did not find any myogenic differentiation of human $\mathrm{AF}$ c-Kit ${ }^{+}$cells after transplantation into the skeletal muscle of SCID mice (Gekas et al., 2010). Myogenic differentiation of AF cells can be induced in vitro by DNA demethylation (e.g., using chemicals such as 5-aza-2'deoxycytidine), co-culture with myoblasts or myogenic cell lines, or directly with in vivo muscle transplantation (De Coppi et al., 2007; Gekas et al., 2010; Ma et al., 2012; Yang et al., 2012), but all these approaches result in the induction of MYOD expression. In fact, by transfecting human AFS cells with MYOD lentivirus, Kim and co-workers demonstrated that human cells also were able to differentiate into myogenic lineage in vitro and in vivo, after injection into injured muscles of immunodeficient BALB/cSlc-nu mice (Kim et al., 2013). All these data indicate that stem cells obtained from discarded AF could be considered good candidates for deeper research and investigation on their ability to differentiate into myogenic cells. Further analyses must be performed to make these cells more committed and at the same time safe for future clinical applications using, for instance, non-viral system such as Piggy Bac or Sleeping Beauty transposons (Izsvak et al.,
2009). These tools allow modifying cells by inserting new genes, ensuring a constitutive genetic integration of the insertion and opening possible way to cure genetic defects.

\section{CONCLUSION}

Muscle pathologies are devastating diseases and nowadays researchers still make efforts to find a cure and not a therapy alone. It has been demonstrated that, after injection in injured or diseased muscle, fetal stem cells act through a mechanism that is mostly due to a bystander effect rather than a direct differentiation. The indirect action is mainly supposed to enhance the production of cytokines, such as VEGF, that stimulate the temporary restoring of the tissue function. To obtain a long lasting action due to efficient cell integration and tissue repopulation, fetal stem cells need to be genetically modified, forcing their differentiation in tissue-specific cells. Nevertheless, the development of safe genetic manipulation methods could make cells of fetal origin appealing for therapeutic application.

Conversely, the long-term positive effect observed using freshly isolated murine AFS cells, highlights that they could have a decisive role in replenishing the muscle stem cell niche, which represent the reservoir of cells able to rescue the defect. Indeed, AFS cells are a safe and immune-privileged cell source prone to integrate in muscle tissue. This knowledge opens the challenge to improve the culture protocol for the AFS cells of human origin, which, so far, is still a limit to overcome for future clinical application to treat genetic and non-genetic muscle dysfunctions (dystrophies, skeletal muscle malformations, traumatic injuries).

\section{ACKNOWLEDGMENTS}

We would like to thank Anilkumar Dave for helpful comments. Michela Pozzobon, Martina Piccoli, and Chiara Franzin are supported by Fondazione Istituto di Ricerca Pediatrica Città della Speranza, Padova, Italy. Paolo De Coppi is funded by the Great Ormond Street Hospital Charity.

\section{REFERENCES}

Akizawa, Y., Kanno, H., Kawamichi, Y., Matsuda, Y., Ohta, H., Fujii, H., et al. (2013). Enhanced expression of myogenic differentiation factors and skeletal muscle proteins in human amnion-derived cells via the forced expression of MYOD1. Brain Dev. 35, 349-355. doi:10.1016/j.braindev.2012.05.012

Anzalone, R., Lo Iacono, M., Corrao, S., Magno, F., Loria, T., Cappello, F., et al. (2010). New emerging potentials for human Wharton's jelly mesenchymal stem cells: immunological features and hepatocyte-like differentiative capacity. Stem Cells Dev. 19, 423-438. doi:10.1089/scd.2009.0299

Ballen, K. K. (2005). New trends in umbilical cord blood transplantation. Blood 105, 3786-3792. doi:10.1182/blood-2004-10-4125

Battula, V. L., Treml, S., Abele, H., and Buhring, H. J. (2008). Prospective isolation and characterization of mesenchymal stem cells from human placenta using a frizzled-9-specific monoclonal antibody. Differentiation 76, 326-336. doi:10.1111/j.1432-0436.2007.00225.x

Berardi, E., Annibali, D., Cassano, M., Crippa, S., and Sampaolesi, M. (2014). Molecular and cell-based therapies for muscle degenerations: a road under construction. Front. Physiol. 5:119. doi:10.3389/fphys.2014.00119

Bittner, R. E., Anderson, L. V., Burkhardt, E., Bashir, R., Vafiadaki, E., Ivanova, S., et al. (1999). Dysferlin deletion in SJL mice (SJL-Dysf) defines a natural model for limb girdle muscular dystrophy 2B. Nat. Genet. 23, 141-142. doi:10.1038/13770

Bollini, S., Cheung, K. K., Riegler, J., Dong, X., Smart, N., Ghionzoli, M., et al. (2011). Amniotic fluid stem cells are cardioprotective following acute myocardial infarction. Stem Cells Dev. 20, 1985-1994. doi:10.1089/scd.2010.0424 
Brooke, G., Tong, H., Levesque, J. P., and Atkinson, K. (2008). Molecular trafficking mechanisms of multipotent mesenchymal stem cells derived from human bone marrow and placenta. Stem Cells Dev. 17, 929-940. doi:10.1089/scd.2007.0156

Broxmeyer, H. E. (2010). Will iPS cells enhance therapeutic applicability of cord blood cells and banking? Cell Stem Cell 6, 21-24. doi:10.1016/j.stem.2009.12.008

Broxmeyer, H. E., Douglas, G. W., Hangoc, G., Cooper, S., Bard, J., English, D., et al. (1989). Human umbilical cord blood as a potential source of transplantable hematopoietic stem/progenitor cells. Proc. Natl. Acad. Sci. U.S.A. 86, 3828-3832. doi:10.1073/pnas.86.10.3828

Brunstein, C. G., Baker, K. S., and Wagner, J. E. (2007). Umbilical cord blood transplantation for myeloid malignancies. Curr. Opin. Hematol. 14, 162-169. doi:10.1097/MOH.0b013e32802f7da4

Bujang-Safawi, E., Halim, A. S., Khoo, T. L., and Dorai, A. A. (2010). Dried irradiated human amniotic membrane as a biological dressing for facial burns - a 7-year case series. Burns 36, 876-882. doi:10.1016/j.burns.2009.07.001

Bulfield, G., Siller, W. G., Wight, P. A., and Moore, K. J. (1984). X chromosomelinked muscular dystrophy $(\mathrm{mdx})$ in the mouse. Proc. Natl. Acad. Sci. U.S.A. 81, 1189-1192. doi:10.1073/pnas.81.4.1189

Cairo, M. S., and Wagner, J. E. (1997). Placental and/or umbilical cord blood: an alternative source of hematopoietic stem cells for transplantation. Blood 90, 4665-4678.

Cargnoni, A., Gibelli, L., Tosini, A., Signoroni, P. B., Nassuato, C., Arienti, D., et al. (2009). Transplantation of allogeneic and xenogeneic placenta-derived cells reduces bleomycin-induced lung fibrosis. Cell Transplant. 18, 405-422. doi:10.3727/096368909788809857

Carraro, G., Perin, L., Sedrakyan, S., Giuliani, S., Tiozzo, C., Lee, J., et al. (2008). Human amniotic fluid stem cells can integrate and differentiate into epithelial lung lineages. Stem Cells 26, 2902-2911. doi:10.1634/stemcells.2008-0090

Chang, Y. J., Shih, D. T., Tseng, C. P., Hsieh, T. B., Lee, D. C., and Hwang, S. M. (2006). Disparate mesenchyme-lineage tendencies in mesenchymal stem cells from human bone marrow and umbilical cord blood. Stem Cells 24, 679-685. doi:10.1634/stemcells.2004-0308

Cifuentes-Diaz, C., Frugier, T., Tiziano, F. D., Lacene, E., Roblot, N., Joshi, V., et al. (2001). Deletion of murine SMN exon 7 directed to skeletal muscle leads to severe muscular dystrophy. J. Cell Biol. 152, 1107-1114. doi:10.1083/jcb.152.5.1107

Conconi, M. T., Burra, P., Di Liddo, R., Calore, C., Turetta, M., Bellini, S., et al. (2006). CD105(+) cells from Wharton's jelly show in vitro and in vivo myogenic differentiative potential. Int. J. Mol. Med. 18, 1089-1096. doi:10.3892/ijmm.18.6.1089

Darabi, R., Arpke, R. W., Irion, S., Dimos, J. T., Grskovic, M., Kyba, M., et al. (2012). Human ES- and iPS-derived myogenic progenitors restore DYSTROPHIN and improve contractility upon transplantation in dystrophic mice. Cell Stem Cell 10, 610-619. doi:10.1016/j.stem.2012.02.015

De Coppi, P., Bartsch, G. Jr., Siddiqui, M. M., Xu, T., Santos, C. C., Perin, L., et al. (2007). Isolation of amniotic stem cell lines with potential for therapy. Nat. Biotechnol. 25, 100-106. doi:10.1038/nbt1274

Dekaris, I., and Gabric, N. (2009). Preparation and preservation of amniotic membrane. Dev. Ophthalmol. 43, 97-104. doi:10.1159/000223842

Dellavalle, A., Maroli, G., Covarello, D., Azzoni, E., Innocenzi, A., Perani, L., et al. (2011). Pericytes resident in postnatal skeletal muscle differentiate into muscle fibres and generate satellite cells. Nat. Commun. 2, 499. doi:10.1038/ncomms 1508

Di Trapani, M., Bassi, G., Ricciardi, M., Fontana, E., Bifari, F., Pacelli, L., et al. (2013). Comparative study of immune regulatory properties of stem cells derived from different tissues. Stem Cells Dev. 22, 2990-3002. doi:10.1089/scd.2013.0204

Ditadi, A., De Coppi, P., Picone, O., Gautreau, L., Smati, R., Six, E., et al. (2009). Human and murine amniotic fluid c-Kit+Lin- cells display hematopoietic activity. Blood 113, 3953-3960. doi:10.1182/blood-2008-10-182105

Duclos, F., Straub, V., Moore, S. A., Venzke, D. P., Hrstka, R. F., Crosbie, R. H., et al. (1998). Progressive muscular dystrophy in alpha-sarcoglycan-deficient mice. J. Cell Biol. 142, 1461-1471. doi:10.1083/jcb.142.6.1461

Ende, M., and Ende, N. (1972). Hematopoietic transplantation by means of fetal (cord) blood. A new method. Va. Med. Mon. (1918) 99, 276-280.

Feldkotter, M., Schwarzer, V., Wirth, R., Wienker, T. F., and Wirth, B. (2002). Quantitative analyses of SMN1 and SMN2 based on real-time lightCycler PCR: fast and highly reliable carrier testing and prediction of severity of spinal muscular atrophy. Am. J. Hum. Genet. 70, 358-368. doi:10.1086/338627

Ferguson, V. L., and Dodson, R. B. (2009). Bioengineering aspects of the umbilical cord. Eur. J. Obstet. Gynecol. Reprod. Biol. 144(Suppl. 1), S108-S113. doi:10.1016/j.ejogrb.2009.02.024
Ferrari, G., Cusella-De Angelis, G., Coletta, M., Paolucci, E., Stornaiuolo, A., Cossu, G., et al. (1998). Muscle regeneration by bone marrow-derived myogenic progenitors. Science 279, 1528-1530. doi:10.1126/science.279.5356.1528

Filareto, A., Darabi, R., and Perlingeiro, R. C. (2013). Engraftment of ES-derived myogenic progenitors in a severe mouse model of muscular dystrophy. J. Stem Cell Res. Ther. 10, 1-13. doi:10.4172/2157-7633.S10-001

Fukuchi, Y., Nakajima, H., Sugiyama, D., Hirose, I., Kitamura, T., and Tsuji, K. (2004). Human placenta-derived cells have mesenchymal stem/progenitor cell potential. Stem Cells 22, 649-658. doi:10.1634/stemcells.22-5-649

Gekas, J., Walther, G., Skuk, D., Bujold, E., Harvey, I., and Bertrand, O. F. (2010). In vitro and in vivo study of human amniotic fluid-derived stem cell differentiation into myogenic lineage. Clin. Exp. Med. 10, 1-6. doi:10.1007/s10238-0090060-2

Gilliam, T. C., Brzustowicz, L. M., Castilla, L. H., Lehner, T., Penchaszadeh, G. K., Daniels, R. J., et al. (1990). Genetic homogeneity between acute and chronic forms of spinal muscular atrophy. Nature 345, 823-825. doi:10.1038/345823a0

Gussoni, E., Soneoka, Y., Strickland, C. D., Buzney, E. A., Khan, M. K., Flint, A. F., et al. (1999). Dystrophin expression in the $\mathrm{mdx}$ mouse restored by stem cell transplantation. Nature 401, 390-394. doi:10.1038/43919

Huang, Y. C., Yang, Z. M., Chen, X. H., Tan, M. Y., Wang, J., Li, X. Q., et al. (2009). Isolation of mesenchymal stem cells from human placental decidua basalis and resistance to hypoxia and serum deprivation. Stem Cell. Rev. 5, 247-255. doi:10.1007/s12015-009-9069-x

Hwang, W. Y., Samuel, M., Tan, D., Koh, L. P., Lim, W., and Linn, Y. C. (2007). A meta-analysis of unrelated donor umbilical cord blood transplantation versus unrelated donor bone marrow transplantation in adult and pediatric patients. Biol. Blood Marrow Transplant. 13, 444-453. doi:10.1016/j.bbmt.2006.11.005

in 't Anker, P. S., Noort, W. A., Scherjon, S. A., Kleijburg-Van Der Keur, C., Kruisselbrink, A. B., Van Bezooijen, R. L., et al. (2003). Mesenchymal stem cells in human second-trimester bone marrow, liver, lung, and spleen exhibit a similar immunophenotype but a heterogeneous multilineage differentiation potential. Haematologica 88, 845-852. doi:10.1016/S0301-472X(03)00202-9

Izsvak, Z., Chuah, M. K., Vandendriessche, T., and Ivics, Z. (2009). Efficient stable gene transfer into human cells by the sleeping beauty transposon vectors. Methods 49, 287-297. doi:10.1016/j.ymeth.2009.07.001

Kawamichi, Y., Cui, C. H., Toyoda, M., Makino, H., Horie, A., Takahashi, Y., et al. (2010). Cells of extraembryonic mesodermal origin confer human dystrophin in the mdx model of Duchenne muscular dystrophy. J. Cell. Physiol. 223, 695-702. doi:10.1002/jcp.22076

Kharraz, Y., Guerra, J., Pessina, P., Serrano, A. L., and Munoz-Canoves, P. (2014). Understanding the process of fibrosis in Duchenne muscular dystrophy. Biomed Res. Int. 2014, 965631. doi:10.1155/2014/965631

Kim, D. K., Fujiki, Y., Fukushima, T., Ema, H., Shibuya, A., and Nakauchi, H. (1999). Comparison of hematopoietic activities of human bone marrow and umbilical cord blood CD34 positive and negative cells. Stem Cells 17, 286-294. doi:10.1002/stem. 170286

Kim, J. A., Shon, Y. H., Lim, J. O., Yoo, J. J., Shin, H. I., and Park, E. K. (2013). MYOD mediates skeletal myogenic differentiation of human amniotic fluid stem cells and regeneration of muscle injury. Stem Cell Res Ther. 4, 147. doi: $10.1186 /$ scrt358

Kong, K. Y., Ren, J., Kraus, M., Finklestein, S. P., and Brown, R. H. Jr. (2004). Human umbilical cord blood cells differentiate into muscle in sjl muscular dystrophy mice. Stem Cells 22, 981-993. doi:10.1634/stemcells.22-6-981

Koponen, J. K., Kekarainen, T., E Heinonen, S., Laitinen, A., Nystedt, J., Laine, J., et al. (2007). Umbilical cord blood-derived progenitor cells enhance muscle regeneration in mouse hindlimb ischemia model. Mol. Ther. 15, 2172-2177. doi:10.1038/sj.mt.6300302

Kucia, M., Halasa, M., Wysoczynski, M., Baskiewicz-Masiuk, M., Moldenhawer, S., Zuba-Surma, E., et al. (2007). Morphological and molecular characterization of novel population of CXCR4+ SSEA-4+ Oct-4+ very small embryonic-like cells purified from human cord blood: preliminary report. Leukemia 21, 297-303. doi:10.1038/sj.leu.2404470

Lapan, A. D., Rozkalne, A., and Gussoni, E. (2012). Human fetal skeletal muscle contains a myogenic side population that expresses the melanoma cell-adhesion molecule. Hum. Mol. Genet. 21, 3668-3680. doi:10.1093/hmg/dds196

Lefebvre, S., Burglen, L., Reboullet, S., Clermont, O., Burlet, P., Viollet, L., et al. (1995). Identification and characterization of a spinal muscular atrophydetermining gene. Cell 80, 155-165. doi:10.1016/0092-8674(95)90460-3 
Leung, D. G., and Wagner, K. R. (2013). Therapeutic advances in muscular dystrophy. Ann. Neurol. 74, 404-411. doi:10.1002/ana.23989

Liu, J., Wallace, L. M., Garwick-Coppens, S. E., Sloboda, D. D., Davis, C. S., Hakim, C. H., et al. (2014). RNAi-mediated gene silencing of mutant myotilin improves myopathy in LGMD1A mice. Mol Ther Nucleic Acids 3, e160. doi:10.1038/mtna. 2014.13

Lorson, C. L., Strasswimmer, J., Yao, J. M., Baleja, J. D., Hahnen, E., Wirth, B., et al. (1998). SMN oligomerization defect correlates with spinal muscular atrophy severity. Nat. Genet. 19, 63-66. doi:10.1038/ng0598-63

Ma, X., Zhang, S., Zhou, J., Chen, B., Shang, Y., Gao, T., et al. (2012). Clonederived human AF-amniotic fluid stem cells are capable of skeletal myogenic differentiation in vitro and in vivo. J. Tissue Eng. Regen. Med. 6, 598-613. doi:10.1002/term.462

McGuckin, C., Jurga, M., Ali, H., Strbad, M., and Forraz, N. (2008). Culture of embryonic-like stem cells from human umbilical cord blood and onward differentiation to neural cells in vitro. Nat. Protoc. 3, 1046-1055. doi:10.1038/nprot. 2008.69

McGuckin, C. P., Forraz, N., Baradez, M. O., Navran, S., Zhao, J., Urban, R., et al. (2005). Production of stem cells with embryonic characteristics from human umbilical cord blood. Cell Prolif. 38, 245-255. doi:10.1111/j.1365-2184.2005. 00346.x

Miki, T., Lehmann, T., Cai, H., Stolz, D. B., and Strom, S. C. (2005). Stem cell characteristics of amniotic epithelial cells. Stem Cells 23, 1549-1559. doi:10.1634/ stemcells.2004-0357

Miki, T., Mitamura, K., Ross, M. A., Stolz, D. B., and Strom, S. C. (2007). Identification of stem cell marker-positive cells by immunofluorescence in term human amnion. J. Reprod. Immunol. 75, 91-96. doi:10.1016/j.jri.2007.03.017

Mitsuhashi, S., and Kang, P. B. (2012). Update on the genetics of limb girdle muscular dystrophy. Semin. Pediatr. Neurol. 19, 211-218. doi:10.1016/j.spen.2012.09.008

Nicole, S., Desforges, B., Millet, G., Lesbordes, J., Cifuentes-Diaz, C., Vertes, D., et al. (2003). Intact satellite cells lead to remarkable protection against Smn gene defect in differentiated skeletal muscle. J. Cell Biol. 161, 571-582. doi:10.1083/jcb.200210117

Nunes, V. A., Cavacana, N., Canovas, M., Strauss, B. E., and Zatz, M. (2007). Stem cells from umbilical cord blood differentiate into myotubes and express dystrophin in vitro only after exposure to in vivo muscle environment. Biol. Cell 99, 185-196. doi:10.1042/BC20060075

Park, T. S., Gavina, M., Chen, C. W., Sun, B., Teng, P. N., Huard, J., et al. (2010). Placental perivascular cells for human muscle regeneration. Stem Cells Dev. 20, 451-463. doi:10.1089/scd.2010.0354

Partridge, T. A., Morgan, J. E., Coulton, G. R., Hoffman, E. P., and Kunkel, L. M. (1989). Conversion of mdx myofibres from dystrophin-negative to -positive by injection of normal myoblasts. Nature 337, 176-179. doi:10.1038/337176a0

Pesce, M., Orlandi, A., Iachininoto, M. G., Straino, S., Torella, A. R., Rizzuti, V., et al. (2003). Myoendothelial differentiation of human umbilical cord blood-derived stem cells in ischemic limb tissues. Circ. Res. 93, e51-e62. doi:10.1161/01.RES. 0000090624.04507.45

Piccoli, M., Franzin, C., Bertin, E., Urbani, L., Blaauw, B., Repele, A., et al. (2012). Amniotic fluid stem cells restore the muscle cell niche in a HSA-Cre, Smn(F7/F7) mouse model. Stem Cells 30, 1675-1684. doi:10.1002/stem.1134

Pipes, B. L., Tsang, T., Peng, S. X., Fiederlein, R., Graham, M., and Harris, D. T. (2006). Telomere length changes after umbilical cord blood transplant. Transfusion 46, 1038-1043. doi:10.1111/j.1537-2995.2006.00839.x

Pozzobon, M., Piccoli, M., and De Coppi, P. (2014). Stem cells from fetal membranes and amniotic fluid: markers for cell isolation and therapy. Cell Tissue Bank. 15, 199-211. doi:10.1007/s10561-014-9428-y

Preitschopf, A., Zwickl, H., Li, K., Lubec, G., Joo, G., Rosner, M., et al. (2012). Chondrogenic differentiation of amniotic fluid stem cells and their potential for regenerative therapy. Stem Cell. Rev. 8, 1267-1274. doi:10.1007/s12015-012-9405-4

Prusa, A. R., and Hengstschlager, M. (2002). Amniotic fluid cells and human stem cell research: a new connection. Med. Sci. Monit. 8, RA253-RA257.

Prusa, A. R., Marton, E., Rosner, M., Bernaschek, G., and Hengstschlager, M. (2003). Oct-4-expressing cells in human amniotic fluid: a new source for stem cell research? Hum. Reprod. 18, 1489-1493. doi:10.1093/humrep/deg279
Rota, C., Imberti, B., Pozzobon, M., Piccoli, M., De Coppi, P., Atala, A., et al. (2011). Human amniotic fluid stem cell preconditioning improves their regenerative potential. Stem Cells Dev. 21, 1911-1923. doi:10.1089/scd.2011.0333

Sacco, A., Mourkioti, F., Tran, R., Choi, J., Llewellyn, M., Kraft, P., et al. (2010). Short telomeres and stem cell exhaustion model Duchenne muscular dystrophy in $\mathrm{mdx} / \mathrm{mTR}$ mice. Cell 143, 1059-1071. doi:10.1016/j.cell.2010.11.039

Sakai, H., Sato, T., Sakurai, H., Yamamoto, T., Hanaoka, K., Montarras, D., et al. (2013). Fetal skeletal muscle progenitors have regenerative capacity after intramuscular engraftment in dystrophin deficient mice. PLoS ONE 8:e63016. doi:10.1371/journal.pone.0063016

Salah-Mohellibi, N., Millet, G., Andre-Schmutz, I., Desforges, B., Olaso, R., Roblot, N., et al. (2006). Bone marrow transplantation attenuates the myopathic phenotype of a muscular mouse model of spinal muscular atrophy. Stem Cells 24, 2723-2732. doi:10.1634/stemcells.2006-0170

Sampaolesi, M., Blot, S., D’Antona, G., Granger, N., Tonlorenzi, R., Innocenzi, A., et al. (2006). Mesoangioblast stem cells ameliorate muscle function in dystrophic dogs. Nature 444, 574-579. doi:10.1038/nature05282

Schoemans, H., Theunissen, K., Maertens, J., Boogaerts, M., Verfaillie, C., and Wagner, J. (2006). Adult umbilical cord blood transplantation: a comprehensive review. Bone Marrow Transplant. 38, 83-93. doi:10.1038/sj.bmt.1705403

Tedesco, F. S., Gerli, M. F., Perani, L., Benedetti, S., Ungaro, F., Cassano, M., et al. (2012). Transplantation of genetically corrected human iPSC-derived progenitors in mice with limb-girdle muscular dystrophy. Sci. Transl. Med. 4, $140 \mathrm{ra} 189$. doi:10.1126/scitranslmed.3003541

Toda, A., Okabe, M., Yoshida, T., and Nikaido, T. (2007). The potential of amniotic membrane/amnion-derived cells for regeneration of various tissues. J. Pharmacol. Sci. 105, 215-228. doi:10.1254/jphs.CR0070034

Wang, M., Yang, Y., Yang, D., Luo, F., Liang, W., Guo, S., et al. (2009). The immunomodulatory activity of human umbilical cord blood-derived mesenchymal stem cells in vitro. Immunology 126, 220-232. doi:10.1111/j.1365-2567.2008. 02891.x

Wilschut, K. J., Ling, V. B., and Bernstein, H. S. (2012). Concise review: stem cell therapy for muscular dystrophies. Stem Cells Transl Med 1, 833-842. doi:10.5966/sctm.2012-0071

Yang, D. Y., Sheu, M. L., Su, H. L., Cheng, F. C., Chen, Y. J., Chen, C. J., et al. (2012). Dual regeneration of muscle and nerve by intravenous administration of human amniotic fluid-derived mesenchymal stem cells regulated by stromal cell-derived factor-1alpha in a sciatic nerve injury model. J. Neurosurg. 116, 1357-1367. doi:10.3171/2012.2.JNS111360

Zhao, Y., Jiang, Z., Zhao, T., Ye, M., Hu, C., Yin, Z., et al. (2012). Reversal of type 1 diabetes via islet beta cell regeneration following immune modulation by cord blood-derived multipotent stem cells. BMC Med. 10:3. doi:10.1186/1741-701510-3

Zuba-Surma, E. K., Klich, I., Greco, N., Laughlin, M. J., Ratajczak, J., and Ratajczak, M. Z. (2009). Optimization of isolation and further characterization of umbilical-cord-blood-derived very small embryonic/epiblast-like stem cells (VSELs). Eur. J. Haematol. 84, 34-46. doi:10.1111/j.1600-0609.2009.01352.x

Conflict of Interest Statement: The authors declare that the research was conducted in the absence of any commercial or financial relationships that could be construed as a potential conflict of interest.

Received: 30 June 2014; paper pending published: 22 July 2014; accepted: 05 August 2014; published online: 27 August 2014.

Citation: Pozzobon M, Franzin C, Piccoli M and De Coppi P (2014) Fetal stem cells and skeletal muscle regeneration: a therapeutic approach. Front. Aging Neurosci. 6:222. doi: 10.3389/fnagi.2014.00222

This article was submitted to the journal Frontiers in Aging Neuroscience.

Copyright $\odot 2014$ Pozzobon, Franzin, Piccoli and De Coppi. This is an open-access article distributed under the terms of the Creative Commons Attribution License (CC $B Y$ ). The use, distribution or reproduction in other forums is permitted, provided the original author(s) or licensor are credited and that the original publication in this journal is cited, in accordance with accepted academic practice. No use, distribution or reproduction is permitted which does not comply with these terms. 